\title{
Sex Differences in Tobacco Abstinence: Effects on Executive Functioning
}

\author{
Francesca Eleuteri' ${ }^{1}$, Danila Rusich ${ }^{2}$, Ashok S. Jansari ${ }^{3}$, Lisa S. Arduino ${ }^{2,4^{*}}$ \\ ${ }^{1}$ Donders Institute for Brain, Cognition and Behavior, Nijmegen, Nederland \\ ${ }^{2}$ Department of Human Sciences, LUMSA University, Rome, Italy \\ ${ }^{3}$ Department of Psychology, Goldsmiths College, University of London, London, UK \\ ${ }^{4}$ Institute of Cognitive Sciences and Technologies, CNR, Rome, Italy \\ Email: ^l.arduino@lumsa.it
}

How to cite this paper: Eleuteri, F., Rusich, D., Jansari, A. S., \& Arduino, L. S. (2019). Sex Differences in Tobacco Abstinence: Effects on Executive Functioning. Psychology, 10, 1622-1635.

https://doi.org/10.4236/psych.2019.1012107

Received: March 18, 2019

Accepted: September 21, 2019

Published: September 24, 2019

Copyright (๑) 2019 by author(s) and Scientific Research Publishing Inc. This work is licensed under the Creative Commons Attribution International License (CC BY 4.0).

http://creativecommons.org/licenses/by/4.0/

(c) (i) Open Access

\begin{abstract}
Aims: Several studies suggested that both sex and tobacco abstinence influence some cognitive processes such as memory and attention. However, very few studies have investigated whether males and females differ in executive functions in relation to tobacco abstinence. We investigated the effects of nicotine abstinence on executive functions in both males and females by using a virtual reality task (JEF). Design: A $2 \times 2 \times 8$ mixed ANOVA was performed, with the percentages of task's scores as dependent variable: Condition (Smoking and Abstinence) and Construct [Planning, Prioritization, Selective Thinking, Creative Thinking, Adaptive Thinking, Action Based Prospective Memory (ABPM), Event Based Prospective Memory (EBPM), Time Based Prospective Memory (TBPM)] as within subjects independent variables and Sex as between subject independent variable. Setting: Department of Human Sciences, Lumsa University in Rome. Participants: Thirty adults smokers, all University students, participated in the study (half females) $(M$ age $=24.53$; range $=$ 18 - 35). Measurement: The Virtual Reality task (JEF), which assesses eight cognitive constructs. Findings: The main effect of Construct was significant $(p<0.0001)$ as the interaction between Sex and Construct $(p<0.01)$; post-hoc analysis showed that females obtained the lowest score in creative thinking while males obtained the lowest score in action-based prospective memory. More importantly, the interaction between Condition and Sex was also significant $(p<0.05)$ and post-hoc analysis indicated that males' performance improved in the abstinence condition, whereas females' performance remained quite stable across them. In both groups, event-based and time-based prospective memories obtained the highest scores. Conclusion: The results of this study partly confirmed previous findings about sex differences in cognitive processes and how tobacco abstinence may differently affect males and females. However, the use of a more sensitive ecological tool has permitted to
\end{abstract}


capture isolated elements of executive functioning that reflect theories of fractionated executive processes and better clarify the effects of smoking and sex differences.

\section{Keywords}

Executive Functions, Smoking Abstinence, Sex Differences, Virtual Reality

\section{Introduction}

Several studies suggest that sex plays an important role in mediating the biological and the psychological effects of tobacco abstinence (Carpenter, Upadhyaya, LaRowe, Saladin, \& Brady, 2006; Dickmann, Mooney, Allen, Hanson, \& Hatsukami, 2009; Merritt, Cobb, \& Cook, 2012; Dome, Lazary, Kalapos, \& Rihmer, 2010; Hogle \& Curtin, 2006) and there is also a consistent literature indicating sex differences in cognitive processes such as executive functions (Andreano \& Cahill, 2009; Herlitz \& Rechnman, 2008; Krueger \& Salthouse, 2010; Merritt, Cobb, \& Cook, 2012; McClernon, Kozink, \& Rose, 2008). In the present study we investigated how executive functions may differ between males and females in nicotine abstinence.

Nicotine dependence syndrome is acknowledged as one of the major public health problems in the world; indeed during the 20th century, approximately 1 billion people died of diseases related to the smoking habit (WHO, 2013). Nicotine is an alkaloid acting as an agonist at nicotinic acetylcholine receptors in the brain (nAChRs) and its acute administration in humans is related to mild euphoria and enhancement in cognition (Markou, 2008; Picciotto \& Corrigall, 2002). Persistent nicotine use develops into tolerance mediated by neuroadaptations; therefore after the last cigarette is smoked, a nicotine abstinence syndrome suddenly occurs (Markou, 2008). Abstinence-related signs and symptoms include depression, anxiety, irritable mood, disturbed appetite and reduced cognitive functioning (Shiffman, West, \& Gilbert, 2004). Decreased cognitive functioning is considered as one of the most important relapse factor (Strasser, Kaufmann, Jepson, Perkins, Pickworth, Wileyto et al., 2005) and the key element in the maintenance of smoking in tobacco-dependent individuals (APA, 2000), with strongest evidence in the area of sustained or vigilant attention, working memory, episodic memory and response inhibition (Ashare, Falcone, \& Lerman, 2014; Hirshman, Rhodes, Zinser, \& Merritt, 2004; Kelemen \& Fulton, 2008; Merritt, Cobb, Moissinac, \& Hirshman, 2010; Merritt, Cobb, \& Cook, 2012; Soar, Dawkins, Begum, \& Parrott, 2008). As mentioned above, despite some studies suggest that sex plays an important role in mediating the biological and the psychological effects of tobacco abstinence (e.g. Carpenter et al., 2006) and that there are sex differences in cognitive processes (e.g. Andreano \& Cahill, 2009), very few studies, often with contradictory results, have investigated whether male and female smokers differ in executive functions in relation to tobacco ab- 
stinence (McClernon, Addicott, \& Sweitzer, 2015).

Executive functions (EF) are generally defined as a complex set of cognitive processes that direct and orchestrate the activity of other cognitive systems involved in the execution of goal-directed behaviour such as memory and reasoning (Baddeley, Della Sala, Papagno, \& Spinnler, 1997). The relationship between EFs' performance and tobacco abstinence is demonstrated by the capacity of nicotine to increase the level of brain dopamine in the prefrontal cortex (PFC), where such functions are ascribed (Dawkins, Powell, West, Powell, \& Pickering, 2007; Markou, 2008). Moreover, the theoretical framework explaining the association between cognitive deficits and relapse has been recently supported by evidence demonstrating the role of higher order cognitive control in the maintenance of goal-directed behavior (Ashare, Falcone, \& Lerman, 2014; Hare, Camerer, \& Rangel, 2009; Kouneiher, Charron, \& Koechlin, 2009), suggesting that deficits in prefrontal cortex may interfere with the motivation needed to remain abstinent by decreasing the cognitive control necessary for facing cravings to smoke (Ashare, Falcone, \& Lerman, 2014). The majority of studies evaluating the effects of nicotine on cognitive functions have focused on sustained attention and/or working memory and the general findings stated that abstinence induces a general decrease in performance and that participants reached their baseline cognitive state as soon as nicotine is introduced once again (Atzori, Lemmonds, Kotler, Durcan, \& Boyle, 2008; Beaver, Long, Cole, Durcan, Bannon, Mishra, \& Matthews, 2011; Foulds, Stapleton, \& Swettenham, 1996; McClernon, Addicott, \& Sweitzer, 2015). Nicotine abstinence has been connected also to disruptions in decision making and reward processing (Addicott, Baranger, Kozink, Smoski, Dichter, \& McClernon, 2012), as well as in visual working memory (Dawkins, Powell, West, Powell, \& Pickering, 2007). By contrast verbal fluency and response inhibition have been both found to be ameliorated in abstinence condition (Dawkins, Powell, West, Powell, \& Pickering, 2007). Such abstinence-induced or reduced deficits, reported soon after the last cigarette is smoked (Hendricks, Ditre, Drobes, \& Brandon, 2006) and generally lasting for weeks (Gilbert, McClernon, Rabinovich, Sugai, Plath, Asgaard, \& Botros, 2004), could be considered as predictors of cessation outcomes (Patterson, Jepson, Loughead, Perkins, Strasser, Siegel, \& Lerman, 2010). In the current study we investigated how executive functions may differ between males and females in nicotine abstinence. In order to capture isolated elements of EF, in accordance to theories of cognitive fractionated processes (Miyake, Friedman, Emerson, Witzki, \& Howerter, 2000), we used a Virtual Reality Assessment known as $\mathrm{JEF}^{\circledR}$, Jansari Assessment of Executive Functions (Jansari, Devlin, Agnew, Akesson, Murphy, \& Leadbetter, 2014). This tool is known to have more ecological validity and sensitivity than traditional assessments (Jansari, Froggatt, Edginton, \& Dawkins, 2012). $\mathrm{JEF}^{\circledR}$ examines a range of executive functions concurrently; namely, planning, prioritization, selection, creative thinking, adaptive thinking and three prospective memory measures (time-based, event-based and action-based). Performance is tested independently for each cognitive construct and in addition an average 
performance score across all constructs is also yielded; in this way the researcher can have an overall understanding of the participant's level of executive functions as well as a breakdown of performance on individual elements (Jansari, Devlin, Agnew, Akesson, Murphy, \& Leadbetter, 2014). JEF ${ }^{\circledR}$ resulted to be able to explore the impact of nicotine (Jansari, Froggatt, Edginton, \& Dawkins, 2012) as such as other drugs like ecstasy (Montgomery, Hatton, Fisk, Ogden, \& Jansari, 2010), alcohol (Montgomery, Ashmore, \& Jansari, 2011) and cannabis (Montgomery, Seddon, Fisk, Murphy, \& Jansari, 2012) on cognitive processes.

\section{Material and Method}

\subsection{Participants}

We interviewed 194 individuals (60 males and 134 females), all declaring to be smokers of cigarettes. All participants were students at LUMSA University in Rome. Thirty participants (half females and half males) met all of the study criteria for inclusion in the analyses $(M$ age $=24.53$; range $=18-35$ ). The exclusion criteria were to be only an occasional smoker and not a daily cigarette addicted and this was established through the administration of the shorter version of the Fagerström Test for Nicotine Dependence (FTND), a useful self-report measure of dependency on nicotine (Fagerström, 1978; Heatherton, Kozlowski, Frecker, \& Fagerström, 1991; Fagerström, Russ, Yu, Yunis, \& Foulds, 2012) (see Appendix for FTND questions and scoring). This version of the questionnaire consists of six items, filled out by the smoker and the test scores range from 0 to 10 , with higher scores indicating greater nicotine dependence. Participants were excluded if they score on the FTND was $<4$. There was no significant difference in Fagerström scores for males $(M=4.14, S D=0.90)$ and female participants $(M=$ $4.75, S D=0.89$ ). There was homogeneity in our groups since there were no significant differences for age, years of education and Fagerström scores. Prior to start the experiment, all participants provided an informed consent and the study was approved by the Ethic committee of the University.

\subsection{Task and Procedure}

$\mathrm{JEF}^{\circledR}$ is a virtual reality assessment where the participant is asked to act as an office assistant. Participants first read the scenario and instructions are given about how to navigate around the virtual environment after being given time to practice using the tool. The instrument takes the form of a software that, once activated, looks like an office setting, where the participant is going to begin his/her first work day. It is explained that the manager is absent and therefore he/she can not supervise his/her work. However, the manager has left a list of supplies that need to be executed. This list is referred as to the "Manager's Tasks for Completion" and consists of 10 activities that the participant has to complete in the most appropriate manner for him/herself. In addition to the list of activities already laid out, four requests noticed in the mail arrived during the assessment 
(which asked participant to perform other tasks), and furthermore, there are two other non-explicit tasks that require the participant to respond to a novelty. There are two rooms in the environments, the participant's office and a meeting room, in which a meeting is going to take place forty minutes after the assessment starts; the two rooms are linked by a corridor and the participant can freely move between the one and the other. All the tasks required to the participants take place in these two rooms (see Figure 1).

The tasks refer to eight executive behaviors, considered fundamental in the analysis of executive functions: "planning", "prioritization", "selection", "creative thinking", "adaptive thinking" and three types of "prospective memory" ("action-based", “event-based" and "time-based"). Participants are required to carry out two tasks for each construct and their performance on each task is assessed through predetermined criteria and a corresponding three-level scoring system. Participants receive a score of 0,1 or 2 , depending on how successful they are at reaching the requirements of the task criteria. As an example, for the prioritization construct the participant is required to arrange objects or to schedule events in a certain order which allows to proceed. Scoring are collected on the full completed set of anonymized (numerically coded) data by the test administrator. Performance is scored manually against a strict protocol on a pro-form for which previous studies have demonstrated an interelated reliability ranging between 0.956 and 1.0 for scoring on individual constructs. In total, the $\mathrm{JEF}^{\circledR}$ task takes approximately 40 minutes to be completed. The scores for the tasks are then summed and a percentage score is calculated for each construct. In accordance to previous studies (Rusted \& Trawley, 2006), participants were requested to smoke as they normally do in the Smoking status, and to refrain from smoking for at least 2 hours prior to testing in the Abstinence condition. In order to ensure that participants did in fact abstain from smoking, they were controlled and monitored all the time since the last cigarette by research staff. To check the effect of the measure (such as a practical effect in learning tasks) condition smoking was randomized in a way that half of the participants carried out the first session in Smoking condition and the second in the Abstinence, while for the other half the order was reversed. At each session, participants completed the JEF $^{\circledR}$ (Jansari, Devlin, Agnew, Akesson, Murphy, \& Leadbetter, 2014) in the Italian version. The assessment was administered in a quiet laboratory at Lumsa
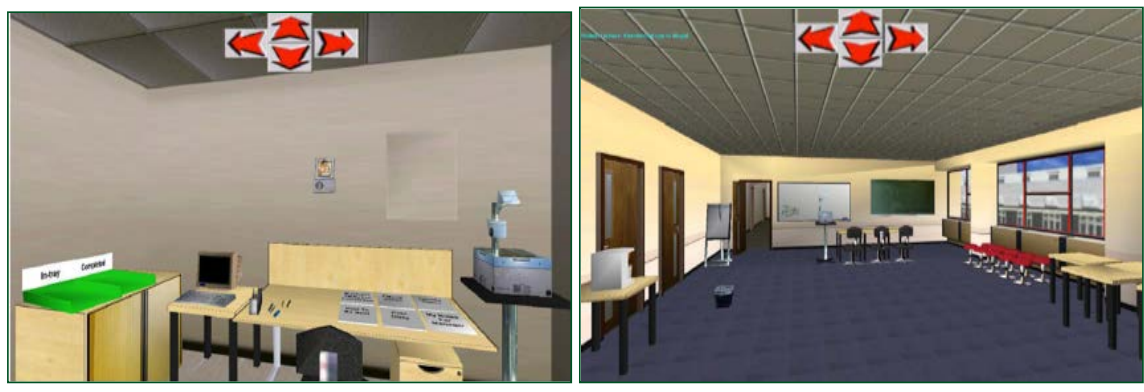

Figure 1. Screen capture of the virtual reality assessment $\mathrm{JEF}^{\odot}$. 
University in Rome in the Department of Human Sciences. Participants were reminded of their right to withdraw at any time throughout the testing session. At the end of the first testing session, appointments were made for participants' second sessions three weeks later. The research complies with the Declaration of Helsinky by the World Medical Association and was authorized by the Ethical Committee of the University.

\section{Results and Discussion}

We performed a $2 \times 2 \times 8$ mixed ANOVA, with the percentages of the correct scores at each of the eight JEF's constructs as dependent variables, Condition (Smoking and Abstinence) and Construct (with 8 levels, Prioritization, Selective Thinking, Creative Thinking, Adaptive Thinking, ABPM, EBPM, TBPM) as the within subjects independent variables and Sex as the between subject variable. When interactions were observed, post-hoc t-test was conducted to clarify the nature of the interaction.

The main effects of Condition and Sex were not significant, while obviously Construct $(\mathrm{F}=(1,7)=10.81, p<0.0001)$ was significant, confirming that these constructs measured different aspects of cognitive processes and that there is a big variability between them. In particular, event-based prospective memory (92.5\%) obtained the highest value which differs significantly to all the other constructs $(p<0.01)$ except for time-based prospective memory $(82 \%)$. Planning, priorization, selection and creativity did not differ from each other but only to respect to the memory measures (planning (62\%) vs. event-based (92.5\%) and time-based (82\%), $p<0.001$ in both cases; priorization (74\%) vs. action-based (58\%) and event-based, $p<0.05$ and $p<0.01$ respectively; selective thinking $(75 \%)$ vs. action-based and event-based, both $p<0.01$; creative thinking (69\%) vs. event-based, $p<0.01$; adaptive thinking (72.5\%) vs. action-based and event-based, $p<0.05$ and $p<0.01$, respectively. More relevant for our study is the significant interaction between Condition and $\operatorname{Sex}(\mathrm{F}(1,28)=5.68, p<0.05)$ and post-hoc analysis indicated that the performance of males improved significantly in the abstinence condition ( $71 \%$ vs. $80 \%, p=0.05$, respectively), whereas females' performance remained equal across conditions (smoking: 71\%; abstinence: $69 \%$ $p>0.1)$.

The interaction between Sex and Construct was also significant $(\mathrm{F}(1,7)=$ $2.84, p<0.01$ ) and post-hoc analysis specified that within the female group the construct with the worst performance was creative thinking (54\%) and that it differed significantly from both the females' event-based prospective memory (EBPM, 93\%, $p<0.0001$ ) and time-based prospective memory (TBPM, 81\%, $p$ $<0.001$ ) and both males' event-based prospective memory (EBPM, 92\%, $p<$ 0.0001 ) and time-based prospective memory (TBPM, 82.5\%, $p<0.01$ ). Both males and females obtained higher scores in two out of three memory constructs and there were no differences between them (males: EBPM: 92\%; TBPM: $82 \%$; females: EBPM: 93\%; TBPM: 81\%). By contrast, within the male group, males' 
action-based prospective memory obtained the lowest scores (54\%), that differed significantly from all the other constructs other than Planning and Priorization (selection: $78 \%, p=0.02$; creative thinking: $83 \%, p=0.001$; adaptive thinking: $78 \%, p=0.02$; EBPM: 92\%, $p=0.000$; TBPM: 0.002; planning: $65 \%, p=0.1$; priorization: $73 \% p>0.01)$. Males's action-based prospective memory differed also significantly from females' EBPM (93\%) and TBPM (81\%). Also in females, action-based prospective memory obtained the worst performance within the memory construct (ABPM: 62\%; EBPM: 93\%; TBPM: 81\%) and differed significantly compared to EBPM $(p<0.01)$. Neither the interaction between Condition and Construct or the three-way interaction Condition by Construct by Sex was significant. In Figure 2 the percentages of correct scores obtained by males and females in the 8 constructs and the overall performance are reported (this latter was not inserted in the statistical analysis).

The aim of this study was to explore whether males and females might differ in the effects of tobacco abstinence on specific aspects of executive functions using a virtual reality assessment (Jansari, Devlin, Agnew, Akesson, Murphy, \& Leadbetter, 2014). Through this test, eight EF's constructs were investigated (planning, prioritization, selection, creative thinking, adaptive thinking, action-based prospective memory, event-based prospective memory and time-based prospective memory) in Smoking and Abstinence (two hours) conditions, in a sample of male and female healthy young adults, that can be considered representative of the adult population. The more interesting result of our study concerns the significant interaction between Sex and Condition, which showed that in Abstinence males performed significantly better than in Smoking condition, whereas females' performance remained stable across the two states. These results are consistent with previous findings where verbal fluency and response inhibition have been shown to improve in abstinent smokers

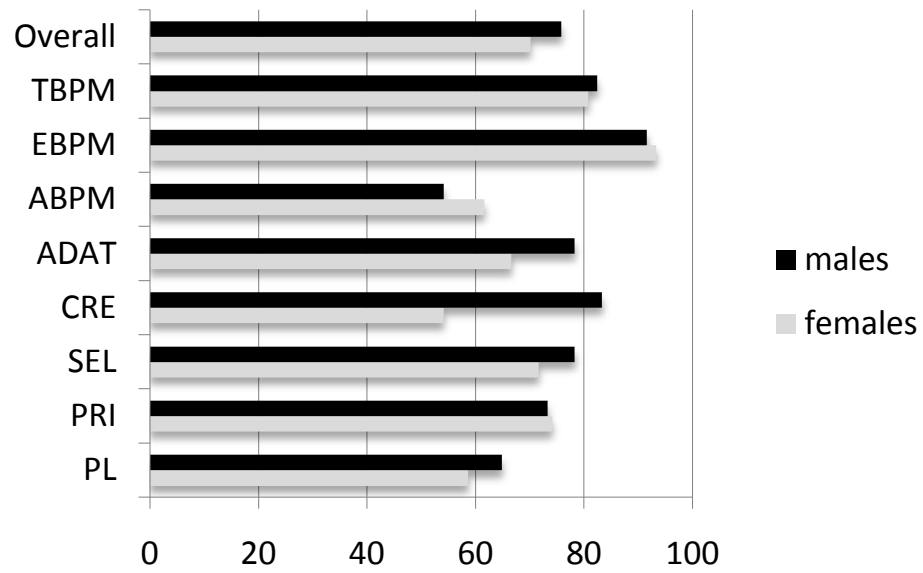

Figure 2. The percentages of correct scores obtained by males and females in the 8 constructs are reported (PL: planning; PRI: priorization; SEL: selection; CRE: creativity; ADAT: adaptive thinking; ABPM: prospective action-based memory; EBPM: prospective event-based memory; TBPM: prospective timed-based memory). OVERALL: all the constructs taken together (that was not included in the statistical analysis). 
(Dawkins, Powell, West, Powell, \& Pickering, 2007) and where females, differently from males, performed equally under conditions of tobacco abstinence as when smoking normally (Merritt, Cobb, Moissinac, \& Hirshman, 2010; Merritt, Cobb, \& Cook, 2012). This is in line with evidence that males and females may use different encoding strategies or recruit different brain regions in order to cope with the effects of tobacco abstinence (Merritt, Cobb, \& Cook, 2012). However, the literature presented also contrasting findings. For example, Van Voorhees, McClernon, Fuemmeler, English, Holdaway, Hallyburton, \& Kollins, (2012) reported that males experience greater cognitive deficits following smoking abstinence when compared to females (Ashare, Falcone, \& Lerman, 2014; Merritt, Cobb, \& Cook, 2012). In this line, Jacobsen, Krystal, Mencl, Westerveld, Frost, \& Pugh (2005) found that males in abstinence performed worst in tasks investigating selective and divided attention. From the literature it emerges a difficulty in comparing results of different studies since, as in the examples just mentioned above, too many methodological differences are present. First, the choice of the cognitive construct as well as the task used in the different studies are often very heterogeneous. Moreover, studies may differ for the type of sample (e.g. clinical vs. typical population, e.g. Van Voorhees et al. (2012), the way in which nicotine is assumed (cigarette vs. gum, e.g. Jansari, Devlin, Agnew, Akesson, Murphy, \& Leadbetter, 2014; Ernst, Heishman, Spurgeon, \& London, 2001; Bohadana, Nilsson, Rasmussen, \& Martinet 2000), the temporal window of abstinence (Atzori, Lemmonds, Kotler, Durcan, \& Boyle, 2008; Beaver, Long, Cole, Durcan, Bannon, Mishra, \& Matthews, 2011; Addicott, Baranger, Kozink, Smoski, Dichter, \& McClernon, 2012; Hirshman, Rhodes, Zinser, \& Merritt, 2004; McClernon, Kozin, Lutz, \& Rose, 2009) or the individual smoking history (Atzori, Lemmonds, Kotler, Durcan, \& Boyle, 2008; Ernst, Heishman, Spurgeon, \& London, 2001). Finally, even the definition and the measurement of smoking addiction and abstinence are quite different thorough the investigations, such as the relative criteria of selection of smokers and non-smokers population (Jacobsen, Krystal, Mencl, Westerveld, Frost, \& Pugh, 2005). Indeed, while in our study we used a 2 hours smoking abstinence time window, others used at least 12 hours (Ashare, Falcone, \& Lerman, 2014; Merritt, Cobb, Moissinac, \& Hirshman, 2010; Merritt, Cobb, \& Cook, 2012; Dawkins, Powell, West, Powell, \& Pickering, 2007). The reasons why we chose the 2-hour time window are essentially related to: 1 ) evidences from the literature indicating that cognitive components of the nicotine withdraw syndrome may develop anytime between 1 and 24 hours of smoking (Bell, Taylor, Singleton, Henningfield, \& Heishman, 1999; Gross, Jarvik, \& Rosenblatt, 1993; Parrott, Garnham, Wesnes, \& Pincock, 1996), 2) the fact that in the previous study by Jansari et al. (2012), where the JEF was used, the same time window was adopted and finally 3) the evidence that a smoker, as selected with our questionnaire, would not be able to resist to smoking for such a long time.

A further result is that the three memory constructs (prospective memory based on event, action and time) were highly sensitive to the experimental ma- 
nipulation when compared to the other constructs, thus seeming to act as a separate set. Both males and females reported high time-based and event-based prospective memory scores. Among the three, action-based prospective memory obtained the lowest results and the interaction by sex qualified this relation, since this was particularly true for males.

Females showed a lower performance on creative thinking not only compared to all the other constructs but also when compared to males' creative thinking and this is consistent with differences in creativity between sex reflected in the literature (Baer \& Kaufman, 2008; Torrance \& Aliotti, 1969). Other research has highlighted the significant interaction between sex and specific constructs. Merritt, Hirshman, Wharton, Stangl, Devlin, \& Lenz (2007) demonstrated a qualitative difference in how males and females respond to a selective attention task and other studies demonstrated a superior episodic memory performance in females, particularly for verbal material (Andreano \& Cahill, 2009; Herlitz \& Rehnman, 2008). More recent formulations of memory processes have underlined the role of inhibitory mechanisms in the processing of efficient remembering (Montgomery, Ashmore, \& Jansari, 2011), where the suppression of irrelevant material is the key in the effective processing of relevant material (Jansari, Froggatt, Edginton, \& Dawkins, 2012). Indeed, there is a growing body of evidence suggesting that nicotine can improve inhibitory control. In this regard, it would be interesting to consider neuromodulatory treatment of the dorsol-lateral-prefrontal cortex (DLPFC), which is the locus of executive functioning and inhibitory control, particularly involved in craving behavior (Fraser \& Rosen, 2012; Boggio, Ligouri, Sultani, Rezende, Fecteau, \& Fregni, 2009; Fregni, Ligouri, Fecteau, Nitsche, Pascual-Leone, \& Boggio, 2008).

\section{Conclusion}

These results open avenues for the exploration of this method as a therapeutic alternative for smoking cessation and also as a mean to change stimulus-induced behavior (Boggio, Ligouri, Sultani, Rezende, Fecteau, \& Fregni, 2009). Anyway, further studies, including variables such as a different time frame of abstinence (Addicott, Baranger, Kozink, Smoski, Dichter, \& McClernon, 2012; Atzori, Lemmonds, Kotler, Durcan, \& Boyle, 2008; Beaver, Long, Cole, Durcan, Bannon, Mishra, \& Matthews, 2011; McClernon, Kozin, Lutz, \& Rose, 2009; Ernst, Heishman, Spurgeon, \& London, 2001), the individual smoking history (Atzori, Lemmonds, Kotler, Durcan, \& Boyle, 2008; Ernst, Heishman, Spurgeon, \& London, 2001), or the hormonal levels (by controlling the menstrual cycle effects) are needed in order to better clarify the effects of nicotine abstinence on gender and executive functioning.

\section{Acknowledgements}

We would like to thank Claudia Falcone for having collaborating in the data collection and all the students for the participating in the research. 


\section{Funding}

This research did not receive grants from any funding agency in the public, commercial and not-for-profit sectors.

\section{Conflicts of Interest}

The authors declare no conflicts of interest regarding the publication of this paper.

\section{References}

Addicott, M., Baranger, D., Kozink, R., Smoski, M., Dichter, G., \& McClernon, J. (2012). Smoking Withdrawal Is Associated with Increases in Brain Activation during Decision Making and Reward Anticipation: A Preliminary Study. Psychopharmacology, 219, 563-573. https://doi.org/10.1007/s00213-011-2404-3

Andreano, J. M., \& Cahill, L. (2009). Sex Influences on the Neurobiology of Learning and Memory. Learning \& Memory, 16, 248-266. https://doi.org/10.1101/lm.918309

APA (2000). Diagnostic and Statistical Manual of Mental Disorders. 4 Text Revision. Washington DC: American Psychiatric Association.

Ashare, R., Falcone, M., Lerman, C. (2014). Cognitive Function during Nicotine Withdrawal: Implications for Nicotine Dependence Treatment. Neuropharmacology, 76, 581-591. https://doi.org/10.1016/j.neuropharm.2013.04.034

Atzori, G., Lemmonds, C. A., Kotler, M. L., Durcan, M. J., \& BoyAtzle, J. (2008). Efficacy of a Nicotine $(4 \mathrm{mg})$-Containing Lozenge on the Cognitive Impairment of Nicotine Withdrawal. Journal of Clinical Psychopharmacology, 228, 667-674. https://doi.org/10.1097/JCP.0b013e31818c9bb8

Baddeley, A., Della Sala, S., Papagno, C., \& Spinnler, H. (1997). Dual-Task Performance in Dysexecutive and Non Dysexecutive Patients with a Frontal Lesion. Neuropsychology, 11, 187-194. https://doi.org/10.1037//0894-4105.11.2.187

Baer, J., \& Kaufman, J. C. (2008). Gender Differences in Creativity. Journal of Creative Behavior, 42, 75-105. https://doi.org/10.1002/j.2162-6057.2008.tb01289.x

Beaver, J. D., Long, C. J., Cole, D. M., Durcan, M. J., Bannon, L. C., Mishra, R. G., \& Matthews, P. M. (2011). The Effects of Nicotine Replacement on Cognitive Brain Activity during Smoking Withdrawal Studied with Simultaneous fMRI/EEG. Neuropsychopharmacology, 36, 1792-1800. https://doi.org/10.1038/npp.2011.53

Bell, S. L., Taylor, R. C., Singleton, E. G., Henningfield, J. E., \& Heishman, S. J. (1999). Smoking after Nicotine Deprivation Enhances Cognitive Performance and Decreases Tobacco Craving in Drug Abusers. Nicotine \& Tobacco Research, 1, 45-52. https://doi.org/10.1080/14622299050011141

Boggio, P. S., Ligouri, P., Sultani, N., Rezende, L., Fecteau, S., \& Fregni, F. (2009). Cumulative Priming Effects of Cortical Stimulation on Smoking Cue-Induced Craving. Neuroscience Letters, 463, 82-86. https://doi.org/10.1016/j.neulet.2009.07.041

Bohadana, A., Nilsson, F., Rasmussen, T., \& Martinet, Y. (2000). Nicotine Inhaler and Nicotine Patch as a Combination Therapy for Smoking Cessation-A Randomized, Double-Blind, Placebo-Controlled Trial. Archives of Internal Medicine, 160, 3128-3134. https://doi.org/10.1001/archinte.160.20.3128

Carpenter, M. J., Upadhyaya, H. Y., LaRowe, S. D., Saladin, M. E., \& Brady, K. T. (2006). Menstrual Cycle Phase Effects on Nicotine Withdrawal and Cigarette Craving: A Review. Nicotine \& Tobacco Research, 8, 627-638. 
https://doi.org/10.1080/14622200600910793

Dawkins, L., Powell, J. H., West, R., Powell, J., \& Pickering, A. (2007). A Double-Blind Placebo Controlled Experimental Study of Nicotine: II-Effects on Response Inhibition and Executive Functioning. Psychopharmacology, 190, 457-467.

https://doi.org/10.1007/s00213-006-0634-6

Dickmann, P. J., Mooney, M., Allen, S., Hanson, K., \& Hatsukami, D. (2009). Nicotine Withdrawal and Craving in Adolescents: Effects of Sex and Hormonal Contraceptive Use. Addictive Behaviors, 34, 620-623. https://doi.org/10.1016/j.addbeh.2009.03.033

Dome, P., Lazary, J., Kalapos, M. P., \& Rihmer, Z. (2010). Smoking, Nicotine and Neuropsychiatric Disorders. Neuroscience and Biobehavioral Reviews, 34, 295-342. https://doi.org/10.1016/j.neubiorev.2009.07.013

Ernst, M., Heishman, S. J., Spurgeon, L., \& London, E. D. (2001). Smoking History and Nicotine Effects on Cognitive Performance. Neuropsychopharmacology, 25, 313-319. https://doi.org/10.1016/S0893-133X(01)00257-3

Fagerström, K. (1978). Measuring Degree of Physical Dependency to Tobacco Smoking with Reference to Individualization of Treatment. Addictive Behaviors, 3, 235-241. https://doi.org/10.1016/0306-4603(78)90024-2

Fagerström, K., Russ, C., Yu, C. R., Yunis, C., \& Foulds, J. (2012). The Fagerström Test for Nicotine Dependence as a Predictor of Smoking Abstinence: A Pooled Analysis of Varenicline Clinical Trial Data. Nicotine \& Tobacco Research, 14, 1467-1473. https://doi.org/10.1093/ntr/nts018

Foulds, J., Stapleton, J., \& Swettenham, J. (1996). Cognitive Performance Effects of Subcutaneous Nicotine in Smokers and Never-Smokers. Psychofarmacology, 127, 31-38. https://doi.org/10.1007/BF02805972

Fraser, P. E., \& Rosen, A. C. (2012). Transcranial Direct Current Stimulation and Behavioral Models of Smoking Addiction. Frontiers in Psychiatry, 3, 79. https://doi.org/10.3389/fpsyt.2012.00079

Fregni, F., Ligouri, P., Fecteau, S., Nitsche, M. A., Pascual-Leone, A., \& Boggio, P. S. (2008). Cortical stimulation of the Prefrontal Cortex with Transcranial Direct Current Stimulation Reduces Cue-Provoked Smoking Craving. The Journal of Clinical Psychiatry, 69, 32-40. https://doi.org/10.4088/JCP.v69n0105

Gilbert, D. G., McClernon, F. J., Rabinovich, N. E., Sugai, C., Plath, L. C., Asgaard, G., \& Botros, N. (2004). Effects of Quitting Smoking on EEG Activation and Attention Last for More than 31 Days and Are More Severe with Stress, Dependence, DRD2 A1 Allele, and Depressive Traits. Nicotine \& Tobacco Research, 6, 249-267. https://doi.org/10.1080/14622200410001676305

Gross, T. M., Jarvik, M. E., \& Rosenblatt, R. M. (1993). Nicotine Abstinence Produced Content-Specific Stroop Interference. Psychopharmacology, 110, 333-336. https://doi.org/10.1007/BF02251289

Hare, T. A., Camerer, C. F., \& Rangel, A. (2009). Self-Control in Decision-Making Involves Modulation of the vmPFC Valuation System. Science, 324, 646-648. https://doi.org/10.1126/science.1168450

Heatherton, T. F., Kozlowski, L. T., Frecker, R. C., \& Fagerstrom, K. O. (1991). The Fagerstrom Test for Nicotine Dependence: A Revision of the Fagerstrom Tolerance Questionnaire. British Journal of Addiction, 86, 1119-1127. https://doi.org/10.1111/j.1360-0443.1991.tb01879.x

Hendricks, P. S., Ditre, J. W., Drobes, D. J., \& Brandon, T. H. (2006) The Early Time Course of Smoking Withdrawal Effects. Psychopharmacology, 187, 385-396. 
https://doi.org/10.1007/s00213-006-0429-9

Herlitz, A., \& Rehnman, J. (2008). Sex Differences in Episodic Memory. Current Directions in Psychological Science, 17, 52-56. https://doi.org/10.1111/j.1467-8721.2008.00547.x

Hirshman, E., Rhodes, D. K., Zinser, M., \& Merritt, P. (2004). The Effect of Tobacco Abstinence on Recognition Memory, Digit Span Recall, and Attentional Vigilance. Experimental and Clinical Psychopharmacolog, 12, 76-83. https://doi.org/10.1037/1064-1297.12.1.76

Hogle, J. M., \& Curtin, J. J. (2006). Sex Differences in Negative Affective Response during Nicotine Withdrawal. Psychophysiology, 43, 344-356. https://doi.org/10.1111/j.1469-8986.2006.00406.x

Jacobsen, L. K., Krystal, J. H., Mencl, W. E., Westerveld, M., Frost, S. J., \& Pugh, K. R. (2005). Effects of Smoking and Smoking Abstinence on Cognition in Adolescent Tobacco Smokers. Biological Psychiatry, 57, 56-66. https://doi.org/10.1016/j.biopsych.2004.10.022

Jansari, A., Devlin, A., Agnew, R., Akesson, K., Murphy, L., \& Leadbetter, T. (2014). Ecological Assessment of Executive Functions: A New Virtual Reality Paradigm. Brain Impairment, 15, 71-87. https://doi.org/10.1017/BrImp.2014.14

Jansari, A., Froggatt, D., Edginton, T., \& Dawkins, L. (2012). Investigating the Impact of Nicotine on Executive Functions Using a Novel Virtual Reality Assessment. Addiction, 108, 977-984. https://doi.org/10.1111/add.12082

Kelemen, W. L., \& Fulton, E. K. (2008). Cigarette Abstinence Impairs Memory and Metacognition Despite Administration of $2 \mathrm{mg}$ Nicotine Gum. Experimental and Clinical Psychopharmacology, 16, 521-531. https://doi.org/10.1037/a0014246

Kouneiher, F., Charron, S., \& Koechlin, E. (2009). Motivation and Cognitive Control in the Human Prefrontal Cortex. Nature Neuroscience, 12, 939-947. https://doi.org/10.1038/nn.2321

Krueger, L. E., \& Salthouse, T. A. (2010). Differences in Acquisition, Not Retention, Largely Contribute to Sex Differences in Multitrial Word Recall Performance. Personality and Individual Differences, 49, 768-772.

https://doi.org/10.1016/j.paid.2010.06.024

Markou, A. (2008). Neurobiology of Nicotine Dependence. Philosophical Transactions of Royal Society, 363, 3159-3168. https://doi.org/10.1098/rstb.2008.0095

McClernon, F. J., Kozink, R. V., \& Rose, J. E. (2008). Individual Differences in Nicotine Dependence, Withdrawal Symptoms, and Sex Predict Transient fMRI-BOLD Responses to Smoking Cues. Neuropsychopharmacology, 33, 2148. https://doi.org/10.1038/sj.npp.1301618

McClernon, F. J., Kozink, R. V., Lutz, A. M., \& Rose, J. E. (2009). 24-h Smoking Abstinence Potentiates fMRI-BOLD Activation to Smoking Cues in Cerebral Cortex and Dorsal Striatum. Psychopharmacology, 204, 25-35. https://doi.org/10.1007/s00213-008-1436-9

McClernon, F.J., Addicott, M. A., \& Sweitzer, M. M. (2015). Smoking Abstinence and Neurocognition: Implications for Cessation and Relapse. In The Neurobiology and Genetics of Nicotine and Tobacco (pp. 193-227). Cham: Springer. https://doi.org/10.1007/978-3-319-13665-3_8

Merritt, P. S., Cobb, A. R., \& Cook, G. I. (2012). Sex Differences in the Cognitive Effects of Tobacco Abstinence: A Pilot Study. Experimental and Clinical Psychopharmacology, 20, 258-263. https://doi.org/10.1037/a0027414 
Merritt, P. S., Cobb, A. R., Moissinac, L., \& Hirshman, E. (2010). Evidence that Episodic Memory Impairment during Tobacco Abstinence Is Independent of Attentional Mechanisms. Journal of General Psychology, 137, 331-342. https://doi.org/10.1080/00221309.2010.499395

Merritt, P., Hirshman, E., Wharton, W., Stangl, B., Devlin, J., \& Lenz, A. (2007). Evidence for Gender Differences in Visual Selective Attention. Personality and Individual Differences, 43, 597-609. https://doi.org/10.1016/j.paid.2007.01.016

Miyake, A., Friedman, N. P., Emerson, M. J., Witzki, A. H., \& Howerter, A. (2000). The Unity and Diversity of Executive Functions and Their Contributions to Complex 'Frontal Lobe' Tasks: A Latent Variable Analysis. Cognitive Psychology, 41, 49-100. https://doi.org/10.1006/cogp.1999.0734

Montgomery, C., Ashmore, K. V., \& Jansari, A. (2011). The Effects of a Modest Dose of Alcohol on Executive Functioning and Prospective Memory. Human Psychopharmacology, 26, 208-215. https://doi.org/10.1002/hup.1194

Montgomery, C., Hatton, N., Fisk, J., Ogden, R., \& Jansari, A. (2010). Assessing the Functional Significance of Ecstasy-Related Memory Deficits Using a Virtual Paradigm. $\mathrm{Hu}$ man Psychopharmacology, 25, 318-325. https://doi.org/10.1002/hup.1119

Montgomery, C., Seddon, A. L., Fisk, J. E., Murphy, P. N., \& Jansari, A. (2012). Cannabis-Related Deficits in Real-World Memory. Human Psychopharmacology, 27, 217-225. https://doi.org/10.1002/hup.1273

Parrott, A. C., Garnham, N. J., Wesnes, K., \& Pincock, C. (1996). Cigarette Smoking and Abstinence: Comparative Effects upon Cognitive Task Performance and Mood State over 24 Hours. Human Psychopharmacology: Clinical and Experimental, 11, 391-400. https://doi.org/10.1002/(SICI)1099-1077(199609)11:5<391::AID-HUP780>3.0.CO;2-Z

Patterson, F., Jepson, C., Loughead, J., Perkins, K., Strasser, A. A., Siegel, S., \& Lerman, C. (2010). Working Memory Deficits Predict Short-Term Smoking Resumption Following Brief Abstinence. Drug and Alcohol Dependence, 106, 61-64. https://doi.org/10.1016/j.drugalcdep.2009.07.020

Picciotto, M. R., \& Corrigall, W. A. (2002). Neuronal Systems Underlying Behaviors Related to Nicotine Addiction: Neural Circuits and Molecular Genetics. Journal of Neuroscience, 22, 3338-3341. https://doi.org/10.1523/JNEUROSCI.22-09-03338.2002

Rusted, J. M., \& Trawley, S. (2006). Comparable Effects of Nicotine in Smokers and Nonsmokers on a Prospective Memory Task. Neuropsychopharmacology, 31, 1545-1549. https://doi.org/10.1038/sj.npp.1300965

Shiffman, S., West, R. J., \& Gilbert, D. G. (2004). Recommendation for the Assessment of Tobacco Craving and Withdrawal in Smoking Cessation Trials. Nicotine Tobacco Research, 6, 599-614. https://doi.org/10.1080/14622200410001734067

Soar, K., Dawkins, L., Begum, H., \& Parrott, A. C. (2008). The Effects of Cigarette Smoking and Abstinence on Auditory Verbal Learning. Human Psychopharmacology: Clinical and Experimental, 23, 621-627. https://doi.org/10.1002/hup.968

Strasser, A. A., Kaufmann, V., Jepson, C., Perkins, K. A., Pickworth, W. B., Wileyto, E. P., Rukstalis, M., Audrain-McGovern, J., \& Lerman, C. (2005). Effects of Different Nicotine Replacement Therapies on Postcessation Psychological Responses. Addiction Behaviour, 30, 9-17. https://doi.org/10.1016/j.addbeh.2004.04.005

Torrance, E. P., \& Aliotti, N. C. (1969). Sex Differences in Levels of Performance and Test-Retest Reliability on the Torrance Tests of Creative Thinking Ability. The Journal of Creative Behavior, 3, 52-57. https://doi.org/10.1002/j.2162-6057.1969.tb00044.x

Van Voorhees, E., McClernon, F. J., Fuemmeler, B., English, J., Holdaway, A., Hallybur- 
ton, M., \& Kollins, S. (2012). An Examination of Differences in Variables Maintaining Smoking Behavior in Adult Smokers with and without Attention-Deficit/Hyperactivity Disorder. Addiction Research \& Theory, 20, 72-81.

https://doi.org/10.3109/16066359.2011.564692

WHO (2013). Noncommunicable Diseases Fact Sheet. World Health Organization. http://www.who.int/mediacentre/factsheets/fs355/en/

\section{Appendix}

1) How soon after you wake do you smoke your first cigarette?

2) Do you find it difficult to refrain from smoking in places where it is forbidden, for example, church, library, cinema, etc.?

3) Which cigarette would you hate most to give up?

4) How many cigarettes/day do you smoke?

5) Do you smoke more frequently during the first hours after waking than during the rest of the day?

6) Do you smoke if you are so ill that you are in bed most of the day?

The scoring is interpreted as follows:

1 - 2 = low dependance

$3-4=$ low to mod dependance

5 - 7 = moderate dependance

$8+=$ high dependance

In the current study participants were selected if their scoring on the Fagerström Test for Nicotine Dependence (Heatherton, Kozlowski, Frecker, \& Fagerström, 1991) was $\geq 4$. 